DOI https://doi.org/10.15589/znp2019.1(475).36

УДК 502.37:66.094.941:661.16

\title{
ANALYSIS OF QUANTUM-CHEMICAL CALCULATIONS \\ OF ALCOHOLIC HYDROLISIS AS A REAGENT METHOD WITH DISPOSAL OF PHOSPHORUM-PESTICIDES
}

\section{АНАЛІЗ КВАНТОВО-ХІМІЧНИХ РОЗРАХУНКІВ ПЕРЕБІГУ ЛУЖНОГО ГІДРОЛІЗУ ЯК РЕАГЕНТНОГО МЕТОДУ ПІД ЧАС ЗНЕШКОДЖЕННЯ ФОСФОРВМІСНИХ ПЕСТИЦИДІВ}

Roman V. Petruk

prroma07@gmail.com

ORCID: 0000-0002-5128-4053

Galyna D. Petruk

prroma07@gmail.com

ORCID: 0000-0002-3978-1495

\section{Р. В. Петрук,}

канд. техн. наук, доцент

Г. Д. Петрук

канд. техн. наук, доцент

Vinnytsia National Technical University, Vinnytsia State Pedagogical University, Vinnytsia

Вінницький Національний технічний університет, Вінницький державний педагогічний університет, м. Вінниця

\begin{abstract}
Purpose. The purpose of the work is to develop a method of alkaline hydrolysis of phosphorus-containing pesticide preparations using quantum-chemical calculations.

Methodology. The methods of mathematical modeling, quantum chemical calculations using and, in particular, the Hartree-Fock method with 3-21G basis using the ChemBioOffice Ultra software package are used.

Results. Quantum-chemical calculations of alkaline hydrolysis of phosphorus-containing pesticide preparations were performed in the work, using the example of the most characteristic ones: Zolon (Fozolon) and Dimethoate (Bi-58). These calculations, based mainly on the Hartree-Fock method of establishing charges and lengths of interatomic bonds, are clearly confirmed experimentally by chromatographic studies. As a result, the efficiency and environmental feasibility of reagent methods as compared to thermal methods of processing (disposal) of non-conventional pesticide residues, which allow not only to obtain from the primary organic toxic compounds significantly less toxic, mainly inorganic, useful secondary raw material, but also a secondary raw material, are found and harmful effects on humans and the environment.

Scientific novelty: Quantum-chemical calculations of alkaline hydrolysis of pesticides Zolon and Dimethoate were first used using the Hartree-Fock method, which made it possible to identify possible reaction paths and predict the final chemical products, which simplifies the process of reagent disposal of substandard pesticides.

Practical value. The research findings can be used to develop mechanisms for the chemical processing of phosphoruscontaining pesticide preparations in the most efficient way possible, reducing the time spent on experimental laboratory studies.

The use of quantum-chemical calculations allows to simulate the processes of decomposition of complex organic molecules in the environment and to predict possible decay products, which can be used in public administration and in forecasting the risks of production activity.
\end{abstract}

Key words: environmental safety; phosphorus-containing pesticides; alkaline hydrolysis; dimethoate, phosolone.

Анотація. Мета. Метою роботи є розробка методу лужного гідролізу фосфорвмісних пестицидних препаратів за допомогою квантово-хімічних розрахунків.

Методика. У роботі використовуються методи математичного моделювання, методи квантово-хімічних розрахунків, зокрема, метод Хартрі-Фока з базисом 3-21G з використанням пакету програм ChemBioOffice Ultra.

Результати. У роботі здійснено квантово-хімічні розрахунки перебігу лужного гідролізу фосфорвмісних пестицидних препаратів на прикладі найбільш характерних із них: Золону (Фозолону) та Диметоату (Бі-58). Ці розрахунки, що базуються переважно на методі Хартрі-Фока із встановленням зарядів та довжин міжатомних зв'язків, чітко підтверджено експериментально 3 допомогою хроматографічних досліджень. В результаті встановлено ефективність та екологічну доцільність реагентних методів порівняно 3 термічними методами переробки (знешкодження) некондиційних залишків пестицидних препаратів, які дозволяють не 


\section{ТЕХНОЛОГІЇ ЗАХИСТУ НАВКОЛИШНЬОГО СЕРЕДОВИЩА № 1- 2019}

тільки отримувати з первинних органічних токсичних сполук суттєво менш токсичну, переважно неорганічну, корисну вторинну сировину, але значною мірою зменшити їхні екотокси та шкідливий вплив на людину та довкілля.

Наукова новизна. Вперше використано квантово-хімічні розрахунки лужного гідролізу пестицидів Золон та Диметоат за допомогою метод Хартрі-Фока, що дозволило визначити можливі шляхи проходження реакцій та передбачити кінцеві хімічні продукти, що спрощує процес реагентної утилізації некондиційних пестицидів.

Практична цінність. Отримані результати досліджень можна використовувати для розробки механізмів хімічної переробки фосфорвмісних пестицидних препаратів максимально ефективним способом, що дозволяє знижувати витрати часу на експериментальні лабораторні дослідження.

Використання квантово-хімічних розрахунків дозволяє моделювати процеси розпаду складних органічних молекул в довкіллі та прогнозувати можливі продукти розпаду, що може використовуватися у сфері державного управління та під час прогнозування ризиків виробничої діяльності.

Ключові слова: екологічна безпека; фосфорвмісні пестициди; лужний гідроліз; диметоат; фозолон.

\section{ВСТУП}

В Україні з кожним роком накопичується значна кількість високотоксичних промислових органічних відходів, до складу яких належать у тому числі і непридатні до використання та заборонені до застосування пестицидні препарати (В Україні їх ще й досі нараховується близько18 тис. тонн). Нами, враховуючи дефіцит органічної сировини в Україні, запропонована альтернативна термічному знешкодженню технологія реагентної переробки фосфоровмісних пестицидів (ФОП) із збереженням хімічної структури модифікованих діючих речовин та їх послідуючим корисним застосуванням [1]. У попередніх роботах [2] нами було досліджено повний лужний гідроліз пестициду Диметоат, який здійснюється у 9 стадій. Підтвердженням правильності запропонованої схеми $€$ якісне ідентифікування кінцевих продуктів, якими $\epsilon \mathrm{Na}_{3} \mathrm{PO}_{4}, \mathrm{Na}_{2} \mathrm{CO}_{3}, \mathrm{Na}_{2} \mathrm{~S}, \mathrm{CH}_{3} \mathrm{OH}$ для випадку, наприклад, Диметоату.

При цьому якісними та кількісними реакціями було доведено кінцеві сполуки лужного гідролізу, проте проміжні стадії перебігу реакції не досліджувались, оскільки гідроліз проходить одночасно в декілька стадій, а не почергово. Виділення проміжних сполук не входило в задачі дослідження. Проте вивчення механізму перебігу такої реакції може мати цікаві наукові результати та відкрити нові атомно-молекулярні ефекти.

Метою роботи є квантово-хімічне дослідження проміжних стадій лужного гідролізу, створення моделі гідролізу та їі перевірка на інших ПП класу ФОП.

\section{ЕКСПЕРИМЕНТАЛЬНА ЧАСТИНА}

Об'єктами квантово-хімічного дослідження були пестициди Диметоат та Золон. Їх структурні формули наведені на рис. 1 та 2. Ці пестициди належать до групи фосфорвмісних органічних сполук (ФОС). Bсі ПП ФОС мають схожу структуру [3] і тому значною мірою мають схожий (чи однаковий) механізм гідролізу.
Для моделювання квантово-хімічних структур використовували програмний пакет ChemBioOffice Ultra 2010 v12, який містить у своєму складі розрахункові пакети Gamess, Jaguar, Морас та окремо виділені алгоритми MMFF94, MM2 і метод Хюккеля. Програмний пакет Gamess може розраховувати квантово-хімічні властивості молекул за основними методами RHF, UHF, ROHF, AM1, PM3 та інші. Зазвичай абревіатури перерахованих методів названі ім'ям розробників методу. Найбільш розроблені та точні неемпіричні з них сьогодні - це методи Хартрі-Фока (HF), Xappica (програма Gaussian), Ловдіна-Мілікейна (LM), Міллер-Плессе (PM), Хюккеля (Hukkel) тощо.

\section{ОБГОВОРЕННЯ РЕЗУЛЬТАТІВ}

При цьому основними властивостями молекул пестицидів, які досліджувались за допомогою квантово-хімічних розрахунків, були довжини зв'язків та заряди на атомах молекули. За цими показниками можна визначати найбільш уразливі зв'язки, які під час лужного гідролізу будуть розриватись в першу чергу. Лужний гідроліз проводять за допомогою водного розчину лугу, в якому активний гідроксильний компонент з від'ємним зарядом атакує атоми молекули, що мають позитивний заряд. Таким чином, за допомогою програм по квантово-хімічним розрахункам можна розрахувати можливі значення відповідних зарядів на атомах.

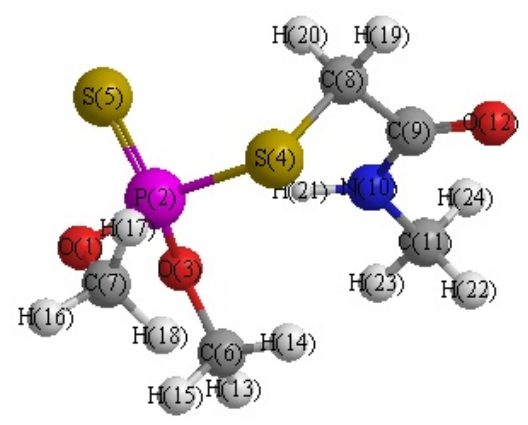

Рис. 1. Структура зв’язків молекули Диметоату 


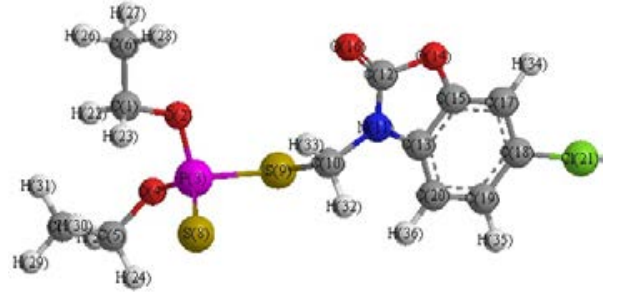

Рис. 2. Структура зв’язків молекули Золону

В програмному пакеті ChemBioOffice можна проводити розрахунки різними алгоритмами та методами. Нами обрано метод RHF/3-21G. Це неемпіричний метод Хартрі-Фока $з$ базисом 3-21G. Він має переваги перед іншими методами і є більш універсальним [4; 5; 7-14].

Отже, розраховані заряди на атомах та довжини зв'язків для молекул Диметоату та Золону занесено до таблиці 1 і 2. Проте у таблицях не наведено заряди на атомах гідрогену та довжину його зв'язку з сусіднім атомом, оскільки їх розрив є малоймовірним, на що вказують і значення зарядів.

Нами раніше було здійснено повий гідроліз деяких фосфоровмісних пестицидів [2; 6] за загальною схемою 1-2:

$$
\begin{aligned}
& \begin{array}{l}
\mathrm{R}_{1}-\mathrm{O}^{-}-\mathrm{P}^{-}-\mathrm{S} \\
\mathrm{R}_{2}-\mathrm{O}^{-}-\mathrm{S}-\mathrm{R}_{3}
\end{array}+\mathrm{NaOH} \longrightarrow \begin{array}{l}
\mathrm{R}_{1}-\mathrm{O}_{-}-\mathrm{P}^{-}-\mathrm{S} \\
\mathrm{R}_{2}-\mathrm{O}^{-}-\mathrm{S}-\mathrm{Na}
\end{array}+\mathrm{R}_{3} \mathrm{OH} \\
& \begin{array}{l}
\mathrm{R}_{1}-\mathrm{O}_{-}-\mathrm{P}-\mathrm{S} \\
\mathrm{R}_{2}=\mathrm{O}^{-}-\mathrm{S}-\mathrm{Na}
\end{array}+7 \mathrm{NaOH} \stackrel{\mathrm{H}_{2} \mathrm{O}}{\longrightarrow} \mathrm{Na}_{3} \mathrm{PO}_{4}+2 \mathrm{Na}_{2} \mathrm{~S}+\mathrm{R}_{1} \mathrm{OH}+\mathrm{R}_{2} \mathrm{OH}
\end{aligned}
$$

$$
\text { де } \mathrm{R}_{1}=\mathrm{R}_{2}=\mathrm{CH}_{3}, \mathrm{C}_{2} \mathrm{H}_{5}, \mathrm{C}_{3} \mathrm{H}_{7} ; \mathrm{R}_{3}=\underset{\mathrm{H}_{2}}{-\mathrm{C}-\mathrm{C}-\mathrm{N}-\mathrm{CH}_{3}(\text { Бi-58), }} \text { (Золон). }
$$

Найбільш імовірним варіантом гідролізу можуть бути зв'язки 1 та 2 на рис. 2. Вони мають близькі за значеннями довжини: $1.82 \AA$ та $1.46 \AA$.

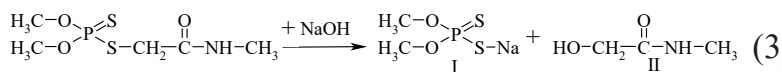

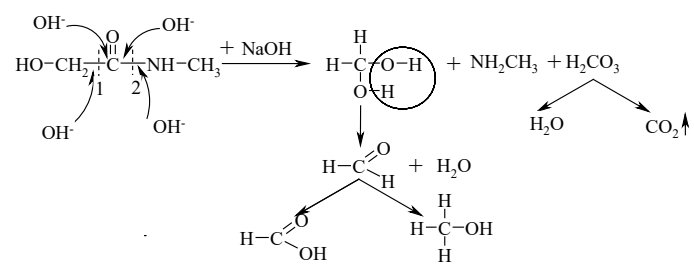

\begin{tabular}{|c|c|c|c|c|c|c|}
\hline Атом & 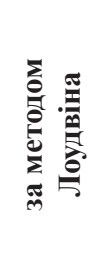 & 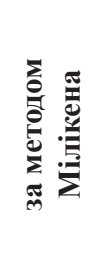 & 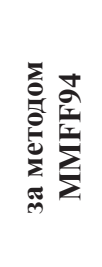 & 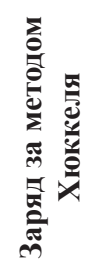 & 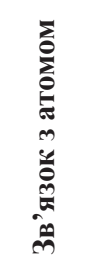 & 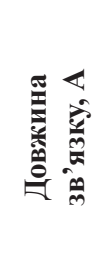 \\
\hline $\mathrm{O}(1)$ & -0.521 & -0.817 & -0.551 & -0.436 & $C(7)$ & 1.4753 \\
\hline $\mathrm{P}(2)$ & 1.108 & 1.327 & 1.467 & 1.770 & $\mathrm{O}(1)$ & 1.6034 \\
\hline $\mathrm{P}(2)$ & & & & & $\mathrm{O}(3)$ & 1.6170 \\
\hline $\mathrm{P}(2)$ & & & & & $\mathrm{S}(4)$ & 2.3693 \\
\hline $\mathrm{O}(3)$ & -0.520 & -0.808 & -0.551 & -0.445 & $\mathrm{C}(6)$ & 1.4864 \\
\hline $\mathrm{S}(4)$ & -0.139 & -0.068 & -0.478 & -0.185 & $\mathrm{C}(8)$ & 1.8974 \\
\hline$S(5)$ & -0.466 & -0.404 & -0.677 & -1.008 & $\mathrm{P}(2)$ & 2.0822 \\
\hline $\mathrm{C}(6)$ & -0.031 & -0.294 & 0.28 & 0.076 & $\mathrm{H}(13)$ & 1.0963 \\
\hline$C(7)$ & -0.020 & -0.274 & 0.28 & 0.075 & $\mathrm{H}(16)$ & 1.0924 \\
\hline $\mathrm{C}(8)$ & -0.318 & -0.754 & 0.291 & -0.133 & $\mathrm{C}(9)$ & 1.5451 \\
\hline $\mathrm{C}(9)$ & 0.300 & 0.896 & 0.569 & 0.391 & $\mathrm{~N}(10)$ & 1.3522 \\
\hline $\mathrm{N}(10)$ & -0.343 & -0.917 & -0.730 & 0.216 & $\mathrm{C}(11)$ & 1.4623 \\
\hline $\mathrm{C}(11)$ & -0.105 & -0.339 & 0.300 & -0.063 & $\mathrm{H}(22)$ & 1.0818 \\
\hline $\mathrm{O}(12)$ & -0.306 & -0.605 & -0.57 & -0.765 & $\mathrm{C}(9)$ & 1.1816 \\
\hline
\end{tabular}

Схема перетворення натрієвої солі диалкілдитіофосфатної кислоти (I) з утворенням ортофосфату:

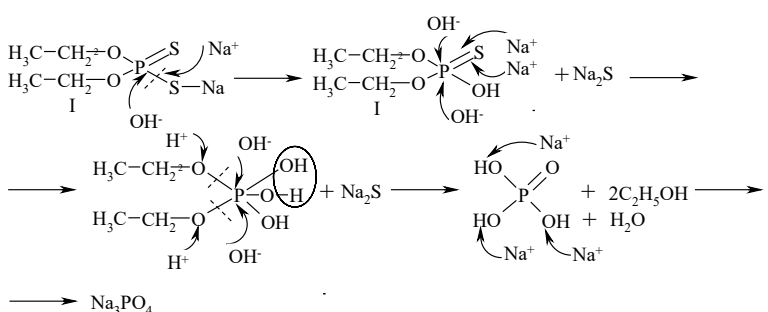

Таблиця 1. Заряди на атомах у молекулі Диметоату та довжини міжатомних зв’язків 
Конкретна схема проходження повного лужного гідролізу для ПП Золон наведена на прикладах рівнянь таких хімічних перетворень:

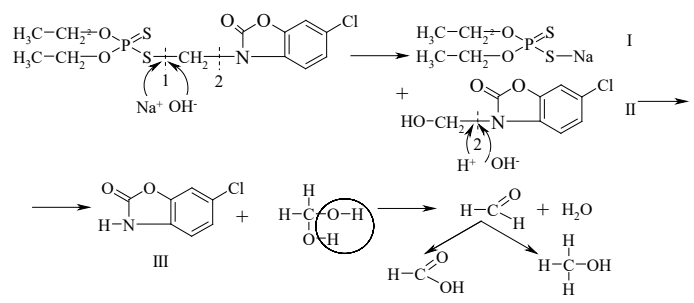

При цьому за допомогою методу газової хроматографії було підтверджено утворення метилового спирту (Рис. 3).<smiles>O=C1Nc2ccc(Cl)cc2NC1CCCCO</smiles>

III

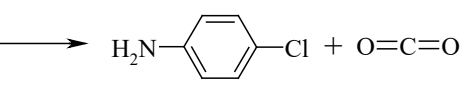

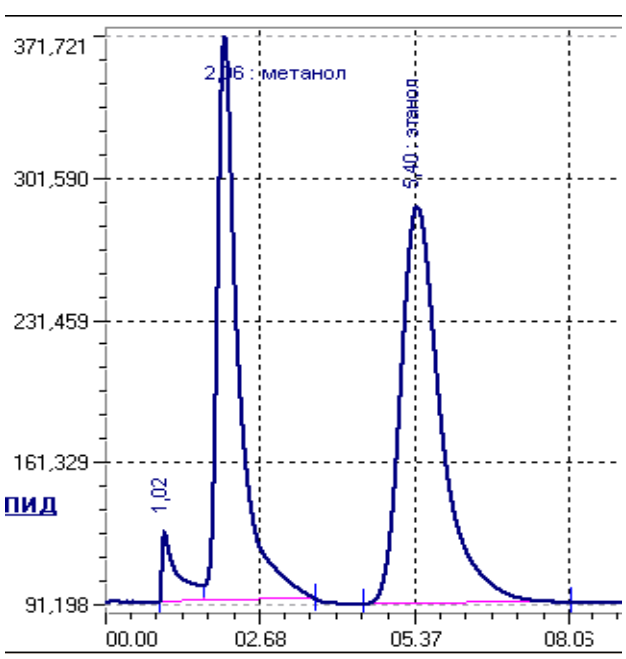

Рис. 3. Зображення хроматограми визначення спитрів у реакційній масі після гідролізу ПП Бі-58

Таблиця 2. Заряди на атомах у молекулі Золону та довжини міжатомних зв'язків

\begin{tabular}{|c|c|c|c|c|c|c|}
\hline Атом & 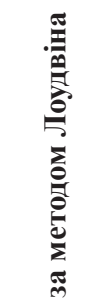 & 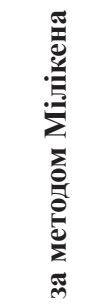 & 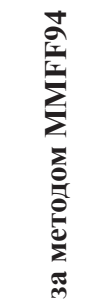 & 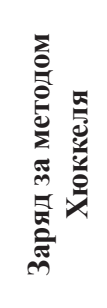 & 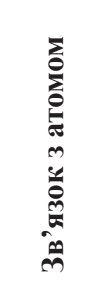 & 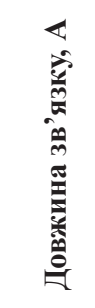 \\
\hline $\mathrm{C}(1)$ & 0.041 & -0.080 & 0.28 & 0.162 & $\mathrm{O}(2)$ & 1.4052 \\
\hline $\mathrm{O}(2)$ & -0.511 & -0.796 & -0.551 & -0.524 & $\mathrm{P}(3)$ & 1.6317 \\
\hline $\mathrm{P}(3)$ & 1.081 & 2.312 & 1.014 & 1.793 & $\mathrm{~S}(9)$ & 2.1158 \\
\hline $\mathrm{O}(4)$ & -0.528 & -0.809 & -0.551 & -0.516 & $\mathrm{P}(3)$ & 1.6314 \\
\hline $\mathrm{C}(5)$ & 0.044 & -0.079 & 0.28 & 0.162 & $\mathrm{O}(4)$ & 1.4046 \\
\hline $\mathrm{C}(6)$ & -0.267 & -0.591 & 0,00 & -0.143 & $\mathrm{C}(1)$ & 1.5265 \\
\hline $\mathrm{C}(7)$ & -0.267 & -0.587 & 0,00 & -0.143 & $C(5)$ & 1.5263 \\
\hline $\mathrm{S}(8)$ & -0.463 & -0.428 & -0.677 & -0.946 & $\mathrm{P}(3)$ & 1.8186 \\
\hline $\mathrm{S}(9)$ & -0.018 & 0.095 & -0.478 & -0.101 & $\mathrm{C}(10)$ & 1.8217 \\
\hline $\mathrm{C}(10)$ & -0.141 & -0.464 & 0.530 & -0.008 & $\mathrm{~N}(11)$ & 1.4671 \\
\hline $\mathrm{N}(11)$ & -0.193 & -1.212 & -0.477 & 0.487 & $\mathrm{C}(13)$ & 1.2661 \\
\hline $\mathrm{C}(12)$ & 0.413 & 1.224 & 0.78 & 0.498 & $\mathrm{~N}(11)$ & 1.2623 \\
\hline $\mathrm{C}(13)$ & 0.018 & 0.529 & 0.117 & 0.025 & & \\
\hline $\mathrm{O}(14)$ & -0.188 & -0.754 & -0.232 & -0.121 & $\mathrm{C}(15)$ & 1.2322 \\
\hline$C(15)$ & 0.098 & 0.368 & 0.082 & 0.238 & $\mathrm{C}(13)$ & 1.3438 \\
\hline $\mathrm{O}(16)$ & -0.325 & -0.635 & -0.57 & -0.849 & $\mathrm{C}(12)$ & 1.2063 \\
\hline $\mathrm{C}(17)$ & -0.120 & -0.136 & -0.15 & -0.219 & $\mathrm{C}(15)$ & 1.3405 \\
\hline $\mathrm{C}(18)$ & -0.109 & -0.429 & 0.177 & 0.104 & $\mathrm{C}(17)$ & 1.3455 \\
\hline$C(19)$ & -0.106 & -0.188 & -0.15 & -0.170 & $\mathrm{C}(20)$ & 1.3443 \\
\hline $\mathrm{C}(20)$ & -0.108 & -0.160 & -0.15 & -0.141 & $\mathrm{C}(13)$ & 1.3385 \\
\hline $\mathrm{Cl}(21)$ & 0.032 & 0.194 & -0.177 & 0.011 & $\mathrm{C}(18)$ & 1.7282 \\
\hline
\end{tabular}


Також хроматографічним методом було підтверджено утворення похідної хлоаніліну.

Хроматографічні дослідження. Хроматографічні дослідження проводились в Інституті медицини праці Академії медичних наук України на газовому хроматографі типу «Кристалюкс 4000» 3 використанням полум'яно-іонізаційного детектора.

За допомогою методу газової хроматографії було підтверджено утворення етилового та метилового спирту.

Приклад проходження наведеної вище реакції підтверджує задовільну відповідність загальної схеми лужного гідролізу.

\section{ВИСНОВКИ}

У результаті проведених досліджень було встановлено повний механізм перебігу реакції гідролізу для ПП Золон та ПП Бі-58 (Диметоат). При цьому виявлено, крім зазначених вище спиртів та інших продуктів лужного гідролізу, утворення додаткової сполуки - мурашиної кислоти.

Проведення квантово-хімічних розрахунків складних хімічних реакцій дозволяє суттєво зменшити час та ресурси на дослідження процесу перебігу реакцій та утворення кінцевих сполук. Метод Хартрі-Фока з базисом 3-21G, що вбудований в програмний продукт ChemBioOffice Ultra, дозволяє автоматизувати розрахунки зарядів на атомах у складних органічних молекулах та рахувати довжини міжатомних зв'язків, що дозволяє виявляти найбільш уразливі місця для гідролізу хімічних сполук.

\section{REFERENCES}

[1] Petruk R., Kostyuk V. Ecological Safety of Pesticide Use in Ukraine/ Roman Petruk, Volodymyr Kostyuk. Environmental Problems. № 2. 2017. P. 115-120. URL: http://science.lpnu.ua/ep/all-volumes-and-issues/volume-2-number-3-2017/ ecological-safety-pesticide-use-ukraine.

[2] Ransky A.P. Full alkaline hydrolysis of non-standard pesticide preparation dimethoate with ecologically safe products. Visnyk of NAU. 2012. № 1. P. 258-265.

[3] Bezvozyuk I., Petruk R., Melnyk T. In Analysis of properties of some persistent organic pollutants Scientific. Works of VNTU. 2014, No. 3. URL: http://praci.vntu.edu.ua/article/view/3747.

[4] Gushurst A.J., Lorgensen W.L. Computer-assisted mechanistic evaluation of organic reactions: reactions of Sulfur and Phosphorus Ylides, Iminophosphoranes, and $\mathrm{P}=\mathrm{X}$-activated anions. Journal of organic chemistry. Vol. 53, No. 15. P. $270-285$.

[5] Hehre W.J., Radom L, Schleyer P v R, Pople J. A. Ab Initio molecular orbital theory. New York : Wiley, 1986.

[6] Petruk R.V. Technological aspects of environmentally friendly processes of domestic phosphorites reduction / Petruk R.V., Petruk G.D., Bezvozyuk I.I., Kriklivii R.D. Journal “Chemistry\&Chemical Technology” Vol. 10, No. 1. 2016. P. 55-62. URL: http://ena.lp.edu.ua/bitstream/ntb/33204/1/8-55-62.pdf.

[7] Melnikov N.N. Chemicals for plant protection (pesticides). Directory / Melnikov N.N., Novozhilov K.V, Pylova T.N / Moscow : Chemistry, 1980. 288 p.

[8] Melnikov N.N. Pesticides. Chemistry, technology and application. / Melnikov N.N / Moscow : Chemistry. 1987.712 p.

[9] Pesticide Analytical Manual. Washington, D.C., USA : Food and Drug Administration, 2011. Vol. I. P. 232.

[10] Manual of Pesticide Residue Analysis. Section Individual Pesticide Residue Analytical Methods. Weinheim, FRG : Deutsche Forschungsgemeinschaft. 1987. Vol. I. P. 159.

[11] Bottomley P. Multi-residue determination of organochlorine, organophosphorus and synthetic pyrethroid pesticides in grain by gas-liquid and high-performance liquid chromatography. / Bottomley P., Baker P.G. Chicago, USA: Analyst, 1984. Vol. 9. P. $85-90$.

[12] Chemistry Laboratory Guidebook, Food Safety and Inspection Service, Science Program. Washington, D.C., USA: United States Department of Agriculture. 2010. Section 5. P. 18-25.

[13] Greve P.A. Analytical Methods for Residues of Pesticides in Foodstuffs. Netherlands : Government Publishing Office, The Hague. 1988. Part I., 5th edition. P. 5-12.

[14] Maybury B.R. Laboratory Manual for Pesticide Residues Analysis in Agricultural Products. Canada, Ottawa, Ont.: Pesticide Laboratory, Food Production and Inspection Branch, Agriculture. 1984. 250 p.

\section{СПИСОК ВИКОРИСТАНОЇ ЛІТЕРАТУРИ}

[1] Петрук Р., Костюк В. Екологічна безпека використання пестицидів в Україні. Екологічні проблеми. № 2.2017. C. 115-120. URL: http://science.lpnu.ua/ep/all-volumes-and-issues/volume-2-number-3-2017/ecological-safety-pesticideuse-ukraine.

[2] Ранський А.П. Повний лужний гідроліз некондиційного пестицидного препарату диметоат з отриманням екологічно безпечних продуктів. Вісник НАУ 2012. № 1. С. 258-265.

[3] Безвозюк I.I., Петрук Р.В., Мельник Т.В Аналіз властивостей деяких стійких органічних забруднювачів. Наукові прайі ВНТУ. 2014. № 3 URL: http://praci.vntu.edu.ua/article/view/3747.

[4] Gushurst A.J., Lorgensen W.L. Computer-assisted mechanistic evaluation of organic reactions: reactions of Sulfur and Phosphorus Ylides, Iminophosphoranes, and $\mathrm{P}=\mathrm{X}$-activated anions. Journal of organic chemistry. Vol. 53, No. 15. P. 270-285. 


\section{ТЕХНОЛОГІЇ ЗАХИСТУ НАВКОЛИШНЬОГО СЕРЕДОВИЩА № 1 - 2019}

[5] Hehre W.J., Radom L, Schleyer P v R, Pople J. A. Ab Initio molecular orbital theory. New York : Wiley,1986.

[6] Петрук Р.В. Технологічні аспекти відновлення екологічно чистих процесів відновлення вітчизняних фосфоритів / Петрук Р.В., Петрук Г.Д., Безвозюк I.І., Крикливий Р.Д. Хімія та хімічна технологія. Vol. 10, No. 1 2016. P. $55-62$. URL: http://ena.lp.edu.ua/bitstream/ntb/33204/1/8-55-62.pdf.

[7] Мельников Н.Н. Химические средства защиты растений (пестициды). Справочник / Мельников Н.Н., Новожилов К.В., Пылова Т.Н. Москва : Химия, 1980. 288с.

[8] Мельников Н.Н. Пестициды. Химия, технология и применение. Москва : Химия. 1987. 712 с.

[9] Pesticide Analytical Manual. Washington, D.C., USA: Food and Drug Administration, 2011. Vol. I. P. 232.

[10] Manual of Pesticide Residue Analysis. Section Individual Pesticide Residue Analytical Methods. Weinheim, FRG: Deutsche Forschungsgemeinschaft. 1987. Vol. I. P. 159.

[11] Bottomley P. Multi-residue determination of organochlorine, organophosphorus and synthetic pyrethroid pesticides in grain by gas-liquid and high-performance liquid chromatography. / Bottomley P., Baker P.G. Chicago, USA: Analyst, 1984. Vol. 9. P. 85-90.

[12] Chemistry Laboratory Guidebook, Food Safety and Inspection Service, Science Program. Washington, D.C., USA: United States Department of Agriculture. 2010. Section 5. P. 18-25.

[13] Greve P.A. Analytical Methods for Residues of Pesticides in Foodstuffs. Netherlands : Government Publishing Office, The Hague. 1988. Part I. 5th edition. P. 5-12.

[14] Maybury B.R. Laboratory Manual for Pesticide Residues Analysis in Agricultural Products. Canada, Ottawa, Ont.: Pesticide Laboratory, Food Production and Inspection Branch, Agriculture. 1984. 250 p. 